\title{
Intelligent Curriculum for Learning Analytics
}

\author{
Mr. Sudarshan \\ Vidya Vardhaka College of \\ Engineering \\ Mysore, India
}

\author{
Mr. Kartik Shrikant Hegde \\ Vidya Vardhaka College of \\ Engineering \\ Mysore, India
}

\author{
Mrs. Laxmi Arun \\ Vidya Vardhaka College of \\ Engineering \\ Mysore, India
}

\begin{abstract}
The present education scenario in higher education emphasizes on a group of individuals, traditional assessment technique and an inefficient learning approach. However, these methods demand better accuracy and reliability since they employ a classical approach of learning which do not provide learner specific content and analyses the learner at the end of his course. Hence the validity of such approaches summonses a review. This paper provides an alternative solution to the drawbacks by developing intelligent curriculum as a customized learning content specifically developed to a learner. Intelligent curriculum forms a part of learning analytics where learning analytics is used to collect, analyze and report learner's data. Intelligent curriculum is developed using educational technological tools like bloom's taxonomy, rasch analysis, learning model, SCORM (Sharable Content Object Reference Model) and MOODLE (Modular Object-Oriented Dynamic Learning Environment). The developed curriculum containing resources for a student focuses on betterment of performances from previous attempts.
\end{abstract}

Keywords: Learning analytics (LA), Intelligent Curriculum, Bloom's Taxonomy, Rasch analysis, SCORM, MOODLE

\section{INTRODUCTION}

Learning is a product of interaction and utilization of the available data. Recently, interest in how this data can be used to improve teaching and learning has also seen unprecedented growth and the emergence of the field of learning analytics. It draws from, and is closely tied to, a series of other fields of study including business intelligence, web analytics, academic analytics, educational data mining, and action analytics.

John P. Campbell and Diana G. Oblinger,[1] working in a premier educational institution "EDUCAUSE", in their research paper Academic Analytics in October 2007, claimed that learning Analytics outlines an approach for sustaining the renewal of educational practice.

There are various ways of developing Learning Analytics [2]. One of them is generating an Intelligent Curriculum. Generated curriculum aims to prime an effective and efficient course design on the relevant issues in the present Education domain. It is aimed to have a greater impact on education by enabling a knowledge-based system, which embodies to handle the practical rules and apply the same in pursuit to reach towards individual style and integrating these styles in educational programs

\section{CONCEPT OF LEARNING ANALYTICS}

According to the $1^{\text {st }}$ International Conference on Learning Analytics and Knowledge(LAK11)[3] held between $27^{\text {th }}$ February 2011 to 1 st March 2011, Learning analytics is the measurement, collection, analysis and reporting of data about learners and their contexts, for purposes of understanding and optimizing learning and the environments in which it occurs.

In this section, we introduce the three important steps of learning analytics.

\subsection{Data collection}

This entails the use of Open-ended or constructed response items (students construct their answer that may have multiple good answers), questions, tasks.

\subsection{Analysis}

Analysis deals with determining the gap between the existing skills with those that are need to be addressed. The results of the analysis are reported using visualizations, tables, charts.

\subsection{Student learning}

Based on the outcome of the analysis, a content pertaining to an individual is developed. This may include resources in the form of audio, video, text, graphics and simulation. However, the resource may differ from person to person and need not be similar to those offered in class.

All the above processes lead to the development of a student centric curriculum which should map with the required needs and relish the task.

\section{GENERATING AN INTELLIGENT CURRICULUM FOR LEARNING ANALYTICS}

The process of developing intelligent curriculum involves several phases and the specialized theories and models incorporated along the process to complete the phase.

\subsection{Phase 1: Framing questions based on Bloom's Taxonomy and Bloom's Keywords}

The initial step involves developing a set of test pool items to the test takers. The test items are taken from a particular course which is under the study from the test takers. Development of test pool items is based on the concept of Bloom's taxonomy model. Each set of test items are developed for every level of Bloom's taxonomy. Each developed item for a level must make use of the Bloom's 
keyword. There are defined keywords for every Bloom's level. Bloom's keyword enables to distinguish between different available levels. Finally, a pool of test items developed for all the Bloom's levels are given to the students. The questions generated are cognitive in nature and could be any of the following types: essays, multiple-choice, true/false, calculations, short answers, descriptive etc.

There are six levels in the taxonomy as shown in Figure 1, moving from the lowest level of complexity to the highest and each layer corresponds exactly to the traits of a learner:

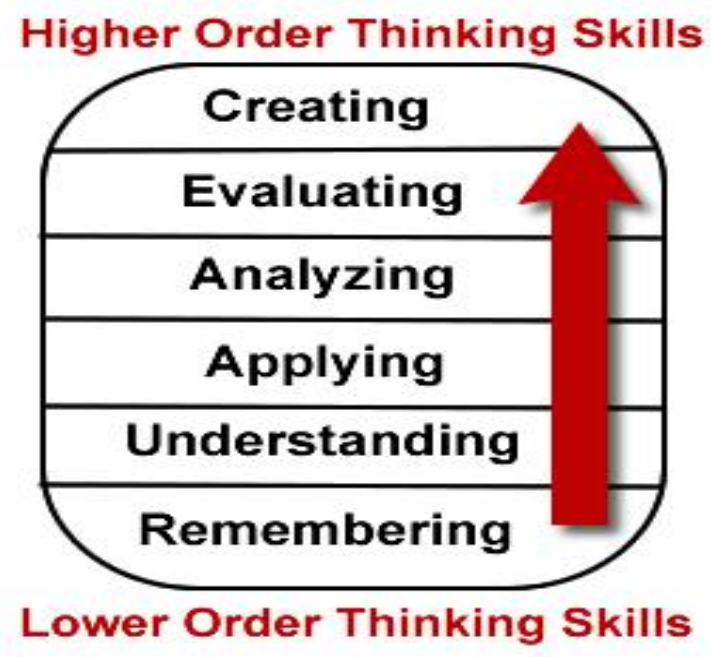

Figure 1: Bloom Taxonomy Levels

\subsubsection{Knowledge/Remembering}

Key Words: defines, describes, identifies, knows

\subsubsection{Comprehension/Understanding}

Key Words: comprehends, converts, defends, distinguishes, estimates

\subsubsection{Application}

Key Words: applies, changes, computes, constructs, demonstrates

\subsubsection{Analysis}

Key Words: analyses, breaks down, compares, contrasts, diagrams

\subsubsection{Evaluation}

Key Words: appraises, compares, concludes

\subsubsection{Creating}

Key Words: categorizes, combines, compiles, composes, creates

\subsection{Phase 2: Uploading test items to an LMS}

In this phase the generated test item pool is uploaded to an LMS. MOODLE is used as an LMS platform to upload the questions. Moodle is a software package for producing Internet-based courses and web sites. It is a global development project designed to support a social constructionist framework of education. The uploaded questions are made available to students to measure their performance. The students can attempt the questions in MOODLE within the specified time in most secured way with a unique username and password.

\subsection{Phase 3: Analysing the performance and generating Intelligent Curriculum}

The performance is analyzed based on a mathematical model- Rasch Model [4] for different parameters and cases.

Rasch models [5] are used for analysing data from assessments to measure variables such as abilities, attitudes, and personality traits.

Analysis using rasch model are carried out through the fundamental rasch formulas. At first, the item difficulty for a bloom's level is calculated using,

$$
\text { Item difficulty }=\mathrm{Nc} / \mathrm{N}
$$

Where, $\quad \mathrm{Nc}=$ Students getting the item correct $\mathrm{N}=$ total number of students

In the next sequence the outcome for a student is obtained in the form of logit as,

$$
\text { Logit= person measure }- \text { item difficulty }
$$

Where, Person measure $(\beta n)=$ score from a level

In the final stage involves the predicting the probability of answering by the student. This step uses the below formula for calculations.

$$
\operatorname{Pr}\left\{X_{n i}=1\right\}=e^{\beta n-\delta i} /\left(1+e^{\beta n-\delta i}\right)
$$

Where, $\quad \operatorname{Pr}=$ probability $\quad \mathrm{e}=$ exponential factor $(2.7182)$

\subsubsection{Prescreening test:}

The prescreening test is the initial stage of analysing the students on a course carried out for all the six levels of Bloom's taxonomy. The test items for all the six levels of Bloom's taxonomy are uploaded on to the LMS and are attempted by a group of five students. The final outcomes of student's S1, S2, S3, S4 and S5 for remembering level are showcased in the Table 1. 
Table 1: Remembering level prescreening test performance

\begin{tabular}{|c|c|c|}
\hline Student & $\begin{array}{c}\text { Item } \\
\text { Difficulty }\end{array}$ & Person Measure \\
\hline S1 & 0.32 & $47.00 \%$ \\
\hline S2 & 0.32 & $56.95 \%$ \\
\hline S3 & 0.32 & $42.06 \%$ \\
\hline S4 & 0.32 & $51.99 \%$ \\
\hline S5 & 0.32 & $51.99 \%$ \\
\hline
\end{tabular}

When a student fails to meet the cut-off criterion set for the each Bloom's level in the pre-screening test, he is provided with the resources required to meet the criterion and thus complete that level. In the table 1, the student's S1 and S3 have failed to meet the required cut-off of 50. Thus student S1 and S3 have to access the resources before the next analysis is carried out for the same level. Student's S2, S4, S5 have crossed the cut-off criterion and have successfully completed the remembering level. The allocation of resources to a below average student is again based on learning model concept. A sample learning model is as shown in Figure 2.

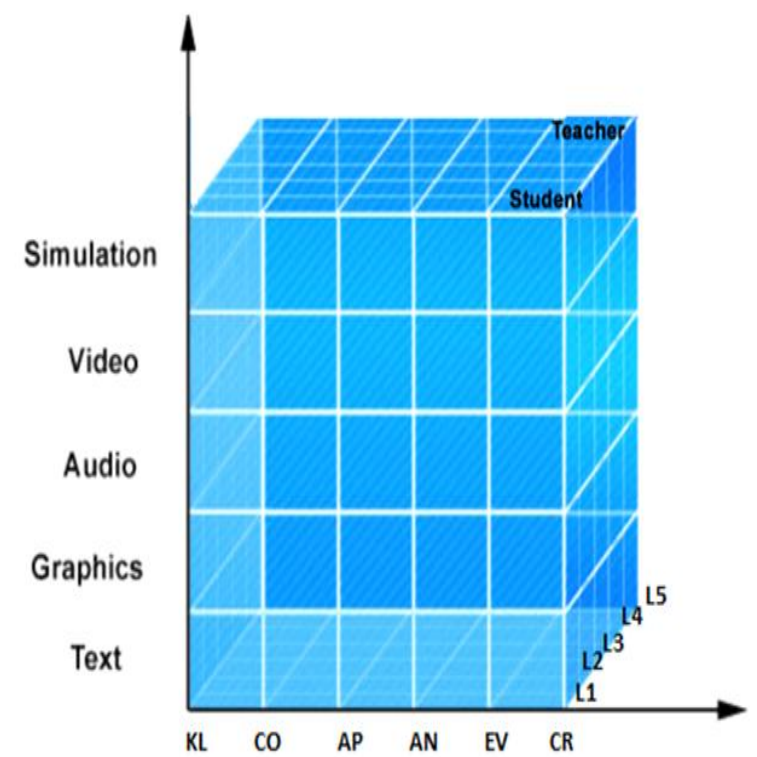

Figure 1: Learning Model

The model is a three dimensional model mapping bloom's levels, learning styles, and the resources need to be provided. An individual is provided with resources after mapping the learning styles and bloom's taxonomy. The abbreviations in Figure 3 are explained in Table 2.

The Table 2 shows how bloom's levels and learning styles are mapped one on one. The six levels of Bloom's are collaborated as five levels and mapped on to five different learning styles.
Table 2: The mapping of bloom's levels and learning styles

\begin{tabular}{|c|c|}
\hline Bloom's Level & Learning Styles \\
\hline Knowledge (KL) & Apprenticeship (L1) \\
\hline Applying (AP) & Incidental (L2) \\
\hline Analysis (AN) & Inductive (L3) \\
\hline Evaluating (EV) & Deductive (L4) \\
\hline Creating (CR) & Discovery (L5) \\
\hline
\end{tabular}

Apprenticeship: Step-by-step procedural learning.

Incidental: Events in the story or case-study with role playing.

Inductive: Numerous examples that confirm to generalized principles.

Deductive: Principles leading to further trends and parametric variations.

Discovery: Experiments leading to data and data leading to a discovery or a principle.

\subsection{Phase 4: Resource Generation}

The resources required for a below average student after the prescreening test is generated using SCORM package [6] and manifest file. Sharable Content Object Reference Model (SCORM) is a collection of standards and specifications for the packaging and sequencing of learning and assessment material in the form of sharable, reusable content object.

The manifest file, included in the package, serves as a guide to the rest of the files. It contains information on resources, metadata and organization.

The generated SCORM complaint object is uploaded to LMS and resources specific to each student who has not completed the particular Bloom's level is provided. The resources are divided into two sets. Initial first set contains the text and graphics and final set contains the audio, video, and simulation. If a student fails in a Bloom's level, then he is provided with the first set of resources containing text and graphics. However, if a student manages to complete the level, then he is suggested with a set of resources which is a choice on the part of learner to utilize or not to utilize.

\subsubsection{Post screening test:}

The post screening test is carried out on a student for a specific Bloom's level in which the student has failed to pass in the prescreening test. The post screening test is carried out in order to verify the improvements of the student after resources are utilized by the student within the prescribed time in Moodle. If a student who has cleared the Bloom's level in prescreening test but chose to attempt the suggested resources, then he is needed to undergo post screening test. If there is no significant improvement in the post screening test, the second set of resources containing audio, video and simulation together with first set of resources is provided and 
again the student is subjected to analysis to check the improvements.

The Table 3 shows the post screening test performance of student S1 and S3 after the first set of resources are provided.

Table 3: Remembering level post screening test performance

\begin{tabular}{|c|c|c|}
\hline Student & $\begin{array}{c}\text { Item } \\
\text { Difficulty }\end{array}$ & $\begin{array}{c}\text { Person } \\
\text { Measure }\end{array}$ \\
\hline S1 & 0.32 & $53.71 \%$ \\
\hline S2 & 0.32 & $46.32 \%$ \\
\hline
\end{tabular}

From the Table 3, it is clear that student $\mathrm{S} 1$ has been successful in completing the level with the first set of resources. But, student S3 has again failed to complete the level. Hence, student S3 is provided with second set of resources along with the first set of resources. The item difficulty for the post screening test remains same as it was for prescreening test.

\subsubsection{Final screening test and Report Generation:}

Final screening test is carried out to students who have failed again in the post screening test and thus accessed the second set of resources in the specified time. Final screening test for student $\mathrm{S} 3$ after providing the second set of resources is shown in Table 4.

Table 4: Remembering/ Knowledge level final screening test performance

\begin{tabular}{|c|c|c|}
\hline Student & $\begin{array}{c}\text { Item } \\
\text { Difficulty }\end{array}$ & $\begin{array}{c}\text { Person } \\
\text { Measure }\end{array}$ \\
\hline S3 & 0.32 & $52.32 \%$ \\
\hline
\end{tabular}

From the Table 4, student S3 has successfully completed the remembering level by meeting the cut-off after the second set of resources are accessed. Hence he has successfully completed the remembering level of Bloom's taxonomy. This cycle continues for all the remaining five levels in the Bloom's taxonomy.

At the end of analysis phase, a report is generated. The report summarizes the performances in pre, post and final screening test and gives the final verdict on levels achieved and improvements to be accomplished and suggests for betterment of results over the course by the teacher.

\section{CONCLUSION}

In this paper, we have considered the advantages of using Learning Analytics in Education domain. The paper presents an efficient tool called Intelligent Curriculum, learner specific content development, for Learning Analytics. The Rasch analysis technique acts as an efficient tool for assessing an individual. The analysis at different phases allows the teacher to verify the quality of resources, the tailored content provided to suit the current skills of the learner and also track the improvements made by the learner. Moodle provides an efficient LMS platform to carry out the tests and allows the learner to access the resources. SCORM helps in development of resources into a package of resources. Thus, we conclude that Intelligent Curriculum fills the bridge between the existing skills, knowledge, and abilities with those that need to be addressed with student centric curriculum.

\subsection{Future Enhancement}

Generate huge test pool - There can be a huge test pool of questions to be selected and given to the learner for the screening

Using Computer Adaptive Training (CAT) or Automated Test Assembly (ATA) for test assembling. Tests can be assembled and then selected randomly which simplifies the role of teacher in forming test set. A linear programming model can be used to accomplish this task.

The minimum sample size required to conduct an analysis using the Rasch is prescribed to be 30 . But this number is big enough in a condition where only a small number of students are subjected to analysis. Hence there is a scope for enhancing the chance of having minimum sample size such as 5 or 10 students.

Use of guessing parameter in Rasch Assessment - Any guessing into the test items by the students can be found by mixing a mathematical along with Rasch model.

A better mathematical model can be used to generate resources instead of learning model concept.

\section{REFERENCES}

[1] John P. Campbell, Peter B. DeBlois, and Diana G. Oblinger, "Academic Analytics: A New Tool for a New Era," EDUCAUSE Review, vol.42, no.4 (July/August2007), pp.40-57.

[2] George Siemens in the Learning Analytics Google Group discussion, August 2010.

[3] Call for Papers of the 1st International Conference on Learning Analytics \& Knowledge (LAK 2011)

[4] Item response theory, a detailed book by F Baker.

[5] Lord, F.M. (1980). Applications of item response theory to practical testing problems. Hillsdale, $\mathrm{NJ}$ : Lawrence Erlbaum Associates.

[6] Creating the first SCORM object by Victor Gonzalez-Barbone, Luis Anido-Rifon ,a Facultad de Ingenieria, Universidad de la Republica, Julio Herrera y Reissig 565, CP 11300 Montevideo, Uruguay, E.T.S.E Telecomunicacion, Universidad de Vigo, Campus Universitario, CP 36310 Vigo, Pontevedra, Spain 